\title{
INFLUENCE OF IMPROVED METHODOLOGY AND INCREASED SPATIAL RESOLUTION ON GRIDDED EMISSIONS
}

\author{
M. S. PLEJDRUP, O.-K. NIELSEN \& H. G. BRUUN \\ Department of Environmental Science, Aarhus University, Denmark
}

\begin{abstract}
Spatial distribution of emissions is a key element in assessing human exposure to air pollution through the use of dispersion modelling. The quality of the spatial emission mapping is crucial for the quality, applicability and reliability of modelled air pollution levels, estimated human exposure and incurred health effects and related costs, all very important information for policymakers in decisions of implementation of environmental policies and measures. Detailed information on spatial distribution of emissions allows for a more targeted regulation, implementing measures focussing on areas where emissions are highest, allowing for more cost-effective initiatives on local, regional and national scale.

The purpose of the MapEIre project, funded by Ireland's Environmental Protection Agency, is to develop a high-resolution spatial mapping of the Irish emission inventory. The work is state-of-the-art and combines a large amount of statistical data with detailed spatial information to allow for a complete spatial emission mapping on a $1 \mathrm{~km}$ by $1 \mathrm{~km}$ resolution.

When comparing the results from the MapEIre project with those of the previous studies, the impact of both methodological refinements and higher spatial resolution becomes very visible. A low resolution, such as the $50 \times 50 \mathrm{~km}$ used in the official reporting, causes important variations to be obfuscated and, if used for air quality modelling, would introduce significant uncertainty. Methodological simplifications can also have significant influence on the results, which has been illustrated in this paper using specific examples comparing the detailed MapEIre methodology with less detailed methodologies used in the previous studies.

The results from MapEIre represent a significant improvement over previous methodologies and will be a strong input for future air quality modelling.

Keywords: air pollution, emission inventory, emission mapping, GeoKey, gridding, spatial emissions, spatial resolution.
\end{abstract}

\section{INTRODUCTION}

Human exposure to air pollution is a significant challenge to human health. The WHO estimates that there were 4.2 million premature deaths in 2016 from urban and rural sources worldwide due to outdoor air pollution [1]. Results by Brandt et al. [2] show that outdoor air pollution caused a total number of 570,000 premature deaths in the year 2011 in Europe. While emissions in Europe are generally decreasing according to the European Environment Agency [3], there are still challenges at the local and regional scale that can only be quantified using high-resolution spatial models.

The impacts from air pollution are not equally distributed and depend on a large number of factors. Detailed information on spatially distributed emissions serves to improve air quality modelling and contributes to a better understanding of the link between air pollution and the related health impacts.

Air pollution, in general, is a transboundary and scale-dependent challenge with global, regional, national and local sources giving rise to large geographical variability and thereby large differences in the geographical distribution of human exposure to air pollution.

Spatial distribution of emissions is a key element in assessing human exposure to air pollution through the use of dispersion modelling. The quality of a spatial distribution depends 
on several aspects, including the completeness, accuracy and resolution. The completeness is determined by the extent to which all emission sources and all pollutants are included. The accuracy depends on the quality of the spatial datasets used and whether the spatial distribution keys (GeoKeys) are suitable proxies for the emission sources. The resolution is a key parameter that has a significant influence on the usefulness of the spatial emissions as a basis for air quality modelling. The higher the spatial resolution, the more details can be reflected and the better of the input to the air quality modelling. The resolution is often limited by the spatial data availability, i.e. if the data are only available at a higher aggregated level such as municipality level, then they do not add value to simply downscale linearly to produce a highresolution distribution, as the input data do not support it. In addition, the higher the spatial resolution, the larger data volumes need to be handled.

Several studies have endeavoured to make a spatial distribution for the whole of Europe. These include the EDGAR system [4] developed by the European Commission Joint Research Centre on a resolution of $0.1^{\circ} \times 0.1^{\circ}$ and the system developed by TNO [5] on a resolution of $1 / 8^{\circ} \times 1 / 16^{\circ}$. In comparison, the national reporting requirements for Parties to the Convention on Long-Range Transboundary Air Pollution (CLRTAP) under the United Nations Economic Commission for Europe (UNECE), which is used in European-wide modelling of air pollution by the Meteorological Synthesizing Centre - West (MSC-W), were until 2015 to report on a $50 \times 50 \mathrm{~km}$ grid. Since 2017 , Parties have been required to report emissions on a grid with a resolution of $0.1^{\circ} \times 0.1^{\circ}[6]$.

Few studies have covered the whole range of pollutants or sectors, and in fact, most of the published studies have focussed on single pollutants [7-10] or single sectors [11-16]. In addition, many studies have not been at the national level but at a city or regional level [17-19]. A few studies have focused on spatial distribution for a range of pollutants at the national level for all emission sectors [20-22].

Based on the change in resolution for the officially submitted gridded data, MSC-W has made a comparison of the spatial correlation between model runs using emissions of the $50 \times 50 \mathrm{~km}$ resolution and the new higher resolution of $0.1^{\circ} \times 0.1^{\circ}$ [23]. The comparison shows that the change to higher-resolution emissions has led to a large improvement in spatial correlation for the vast majorities of European countries.

As a result of the international focus on air quality, the Forum for Air quality Modelling (FAIRMODE [24]) was established in 2007 as a framework for knowledge exchange and capacity building focusing on assessment, emissions, source appointment and planning. FAIRMODE has set up a composite mapping tool holding the best available national, regional and local emission and concentration maps for different EU areas. Results from the MapEIre study have been refined for the Dublin area and included in the EU Composite Map Platform for use in FAIRMODE.

Previously published projects on spatial distribution in Ireland have been done at a resolution of $10 \times 10 \mathrm{~km}[25,26]$, and the official submissions have been done at a resolution of $50 \times 50 \mathrm{~km}$. The MapEIre project increased the resolution to $1 \times 1 \mathrm{~km}$ to improve the usability for air quality modelling and to allow for a more detailed regulation implementing measures targeting areas where the emissions are highest allowing for more cost-effective initiatives. Development of a national spatial emission model covering the entire country allows for assessment of effects of measures on local, regional and national scale. This paper makes comparisons between the previous Irish spatial emissions and the new higherresolution emissions from the MapEIre project to illustrate the increased accuracy that can be gained by changing to a higher resolution. 


\section{METHODOLOGY}

The integrated spatial emission mapping model for Ireland, MapEIre, is developed with the aim to use the most detailed data available regarding information on both emissions and spatial patterns, while still being easy to update as new knowledge becomes available.

The model is built as an integrated database system, aiming at being easy to operate for the end users, but still able to handle the large data amounts and run complex calculations at high speed. This is ensured through a well-organised setup, a clear data concept and precise interrelationships between the incorporated parameters, e.g. via use of primary keys. The built-in simple user interfaces minimise the risk of introduction of errors by the user. The model includes all pollutants in the Irish emission inventory as reported to the CLRTAP for air pollution and to the United Nations Framework Convention on Climate Change for greenhouse gases. The sectoral levels in MapEIre follow the sectors in the corresponding reporting tables (Nomenclature for Reporting [NFR] and common reporting format [CRF]). In total, MapEIre covers 32 pollutants (air pollutants and greenhouse gases) and 177 sub-sectors in the main sectors energy, industrial processes and product use, agriculture, land-use change - land-use change and forestry and waste. The model is linked directly to the data in the NFR and the CRF tables, making it easy to update when recalculations are made in the emission inventory, and ensuring consistency of emission totals in the national and the spatial inventory. Should the scope of the emission inventory change, e.g. with the addition of new pollutants and/or sub-sectors, this can easily be incorporated into the model.

The spatial resolution in MapEIre is $1 \times 1 \mathrm{~km}$, using an orthogonal grid following the 1,000 $\mathrm{m} \mathrm{x}$-axis and $\mathrm{y}$-axis in the TM65/Irish Grid projection (EPSG 29902). The allocation of the national total emissions is based on a large number of spatial distribution keys (GeoKeys), which are normalised tables holding the shares of the national total emission for a given sector and a given pollutant, to be allocated to the individual cells in a pre-defined grid. A description of the GeoKeys, including the methodology and the underlying spatial input data, is provided in Plejdrup et al. [27].

The development of a high-resolution emission model requires the use of detailed highresolution spatial data. The level of detail of the spatial data should preferably match the model resolution, but in some cases, spatial data of such a high level of detail do not exist or are confidential due to data protection regulations. In such cases, the level of detail can be improved by combining information from different spatial data sets and/or by including relevant statistical data with a spatial parameter. Subdivision of low-resolution data to higher spatial resolution should be avoided, as this does not contribute to a more accurate result. However, taking into account the high output resolution, it can be necessary to use spatial data of lower resolution for some emission sources, due to limitation of data availability or as a balancing of the required workload to prepare a GeoKey and the improvement it would make to the spatial emission model. E.g., it may not be worth the effort to use many resources to prepare a very detailed GeoKey for an emission source making up a minor share of the national total emission.

MapEIre uses the best available statistical data and combines it with the best available spatial data. In many cases, it has been possible to get data at a very high resolution such as small areas (SA), which is defined as areas of population generally comprising between 80 and 120 dwellings. SA were designed as the lowest level of geography for the compilation of statistics in line with data protection. High level of detail can be obtained by combining statistical data including a geographical component with digital maps, e.g. by combining traffic counts for observation sites with digital map of the road network. Further refinement 
of the distribution can be made if the digital maps include attribute data related to the emission source that can be included in the methodology, e.g. a split of traffic counts into vehicle types like passenger cars, vans and trucks, which are often included in traffic count data from transport authorities.

\section{RESULTS AND DISCUSSION}

Based on the model, emissions have been mapped with a resolution of $1 \times 1 \mathrm{~km}$ for all pollutants and all sectors, and the output is available as emission maps that can be downloaded from the project website (www.mapeire.dk) as pictures (jpg files) and digital maps (shape files) for use in Geographical Information Systems.

To assess the influence of improving the spatial resolution of gridded emissions, a comparison of three spatial inventories is presented. The current spatial inventory developed as part of the MapEIre project and the previous work that has been carried out in Ireland on a coarser scale. Emission inventories are updated annually and can contain recalculations for all years in the time series. This means that the emission for a specific year can vary between different versions of the emission inventories. Annual updates include updates of activity data, emissions factors and methodologies and introduction of new emission sources. This should be kept in mind as the changes in the emission inventory over the years can complicate the comparison of different spatial emission inventories and lead to misinterpretations.

Some examples of how the more detailed approach has improved the spatial distribution of emissions have been described in the following focussing on some of the sectors with a high emission impact. Spatial emissions are presented on maps, which are prepared with the aim of highlighting the differences of the emission patterns rather than the actual emissions. To enhance the differences and eliminate the influence of changes from recalculations and refinements of the emission calculations to the extent possible, the maps visualise the share of national total emissions. The classification is made using geometrical intervals to streamline the methodology for dividing the data into the classes given in the legend, as using the same classes for all layers in a comparison will conceal the differences in the distribution pattern. The geometric interval methodology is well suited for visualising data that do not follow a normal distribution, or are distinctly skewed, which is the case e.g. for some industrial sectors, where large shares of the emissions come from few point sources and the rest of the emissions come from area sources.

The comparisons presented in Figs. 1-7 are made on sectoral level. It is based on gridded emissions with a resolution of $1 \times 1 \mathrm{~km}$ for the year 2015 and with a resolution of $10 \times 10$ $\mathrm{km}$ for the year 2010 .

The methodology used for road transport is based on the similar approaches for the major roads (national roads), using traffic count data. The gridding is based on data from the National Road Authority's traffic counters including approximately 140 sites in 2010 and approximately 300 sites in 2015 . The residual of the national total mileage is allocated to the remaining roads. In MapEIre, the road network area is used as proxy for mileage, while the 2010 inventory used population density and road length. Use of population density as proxy accumulates emissions in densely populated urban areas as e.g. Dublin, which may overestimate the emission, due to more widespread use of other modes of transport, e.g. bikes and public transport. The MapEIre model allocates $25 \%$ of the emissions to the Dublin area, while use of population as proxy would allocate $55 \%$ of the emissions to Dublin. Using road area as proxy allocates the same emissions to roads with the same width regardless of some being heavily trafficked and others being less heavily trafficked. 

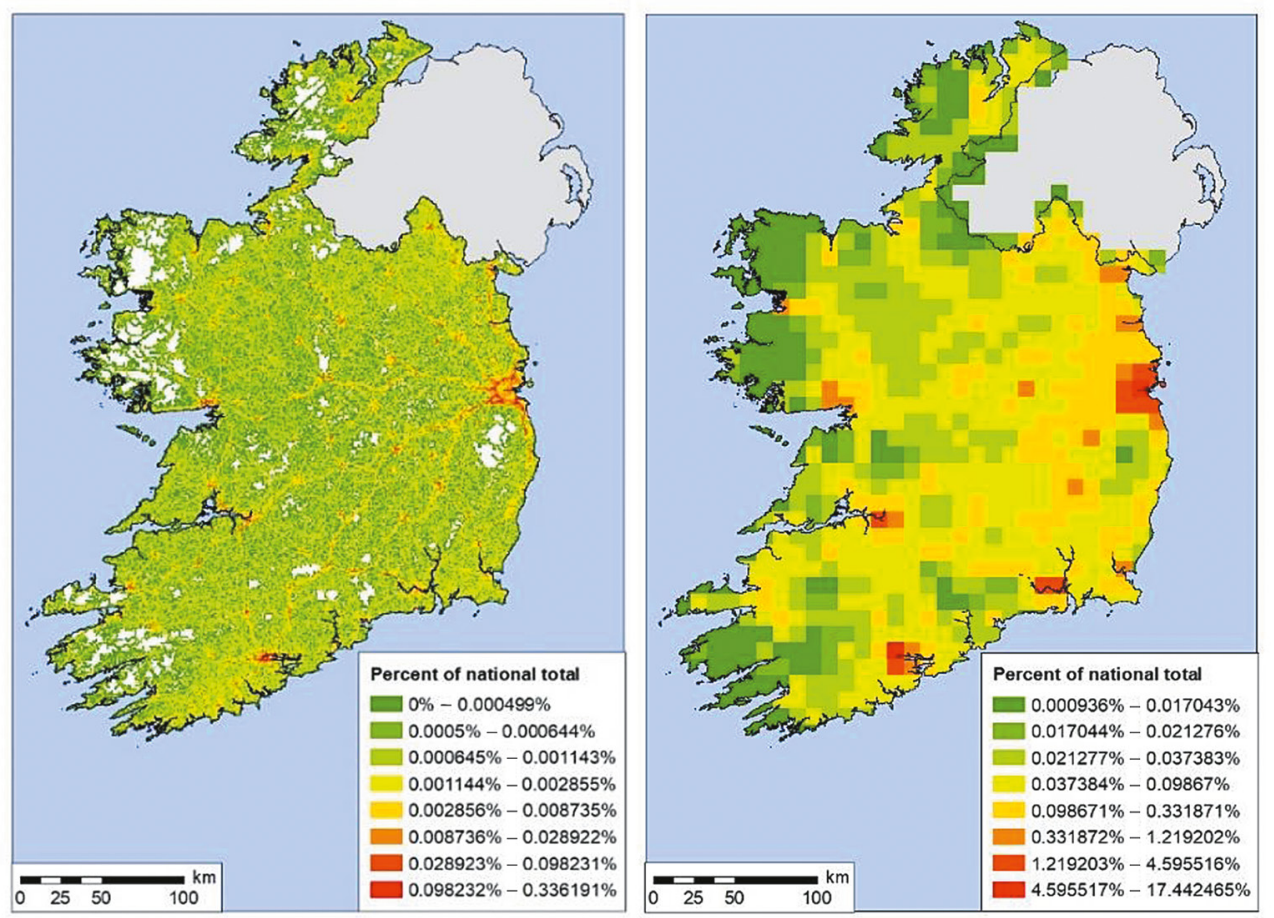

Figure 1: Share of $\mathrm{NO}_{\mathrm{x}}$ emissions from road transport on a spatial resolution of (a) $1 \times 1 \mathrm{~km}$ and (b) $10 \times 10 \mathrm{~km}$.

Using a higher spatial resolution enables the road network to be reflected in more detail, which makes the spatial emissions more useful for modelling of local air quality and human exposure (see Fig. 1.)

The 2010 methodology allocated emissions from agricultural machinery to pasture and arable land. The improved MapEIre methodology allocates emissions to cropland and improved grassland based on the Land Parcel Identification System (LPIS), according to distribution of mileage for agricultural machinery on county level provided by the Central Statistics Office (CSO).

Combining mileage statistics and the LPIS map improves gridding compared to allocating emissions evenly to the areas, where it is assumed to occur. Cropland is mainly found in the eastern and southern parts of Ireland, while grassland is found in the western and northern parts of the country. This is reflected in the spatial model, as intensive cropland cultivation requires the use of more machinery than extensive grassland cultivation. The regional variation caused by different land use is evident from the maps in Fig. 2.

Gridding of $\mathrm{NH}_{3}$ takes its starting point in the agricultural census by the CSO, which includes animal numbers on electoral districts (EDs) for dairy cows and other cattle, and on county level for sheep, goats, horses, mules and asses, swine and poultry. The 2010 gridding distributed emissions between EDs based on animal numbers and evenly to the areas of the individual EDs. The same basic approach is used in MapEIre with the exception that emissions are allocated to areas classified as farmyards or buildings in the LPIS. Emissions from 

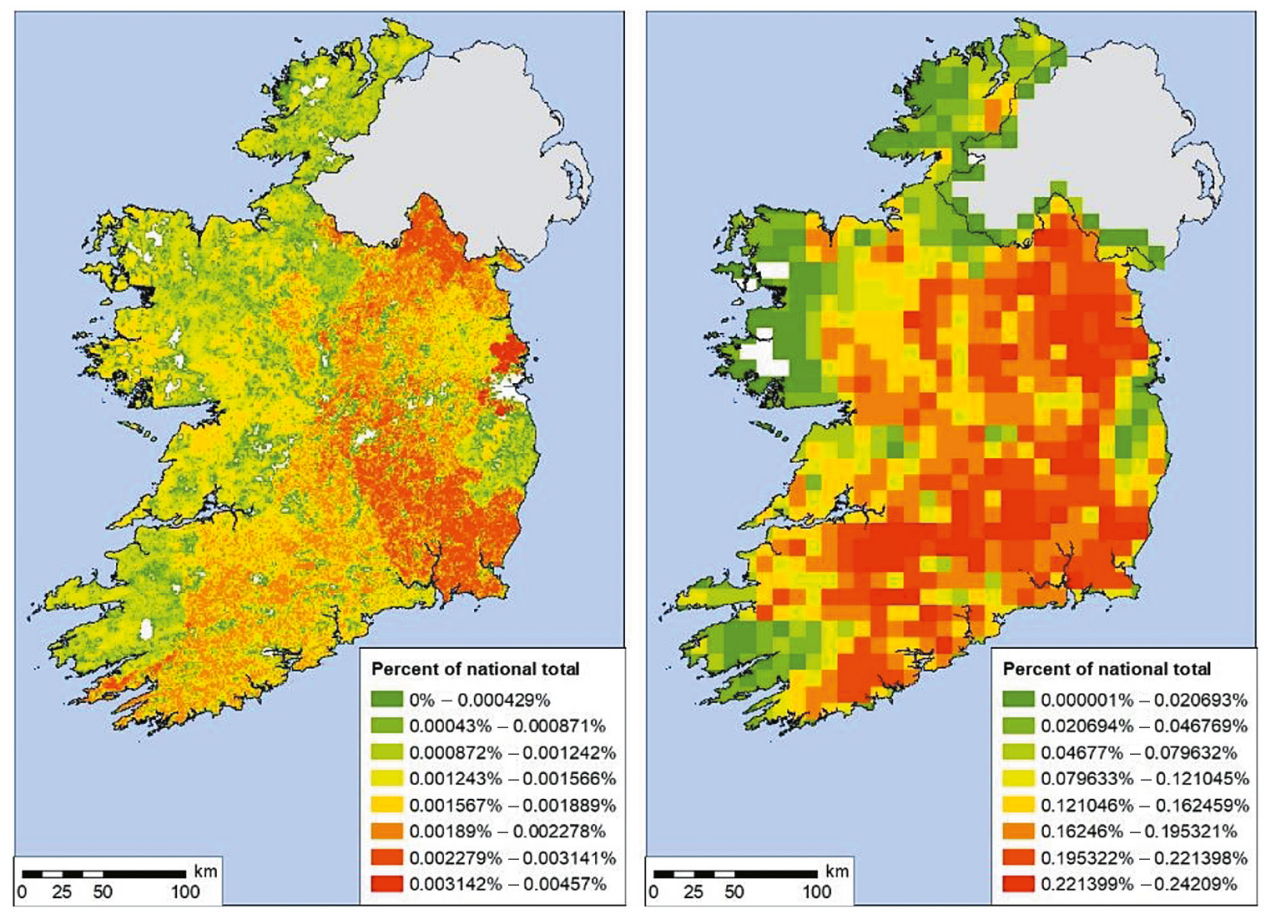

Figure 2: Share of $\mathrm{NO}_{\mathrm{x}}$ emissions from off-road mobile sources on a spatial resolution of (a) $1 \times 1 \mathrm{~km}$ and (b) $10 \times 10 \mathrm{~km}$.

sheep, goats, horses, mules and asses, swine and poultry are allocated to rural areas based on animal numbers by livestock species. Gridding for sheep and horses for 2015 was improved by using animal numbers on ED level and following the same methodology as used for dairy cows and other cattle. Goats, mules and asses follow the same methodology as for dairy cows and other cattle, but based on county-level data, which is the highest spatial resolution available for those animal species.

Large improvements are introduced for pigs and poultry in MapEIre. A comprehensive study carried out by University College Dublin in the AmmoniaN2K project [28] assigned animal numbers from annual environmental reports to the locations of the Industrial Emissions Directive [29] licensed pig and poultry farms in 2016. In Ireland, there is no publicly available database of below threshold pig and poultry houses, but the AmmoniaN2K project has identified the locations of a significant proportion of these farms which were included in MapEIre. The data cover the main part of the pig and poultry production (broilers and laying hens, separately). Common GeoKeys are prepared for pigs and poultry species as an average of licensed and unlicensed animals, based on share of total animal number by species.

The $\mathrm{NH}_{3}$ emission map based on MapEIre has a much higher level of detail, as emissions from enteric fermentation and manure management are allocated to the farms and not evenly by ED or to rural areas. From Fig. 3, it can be seen that the improved methodology and the higher spatial resolution significantly change the composition of the map, with the emission being focussed on the farmhouses and pastures rather than following a uniform distribution based on an evenly allocation across the whole area. 

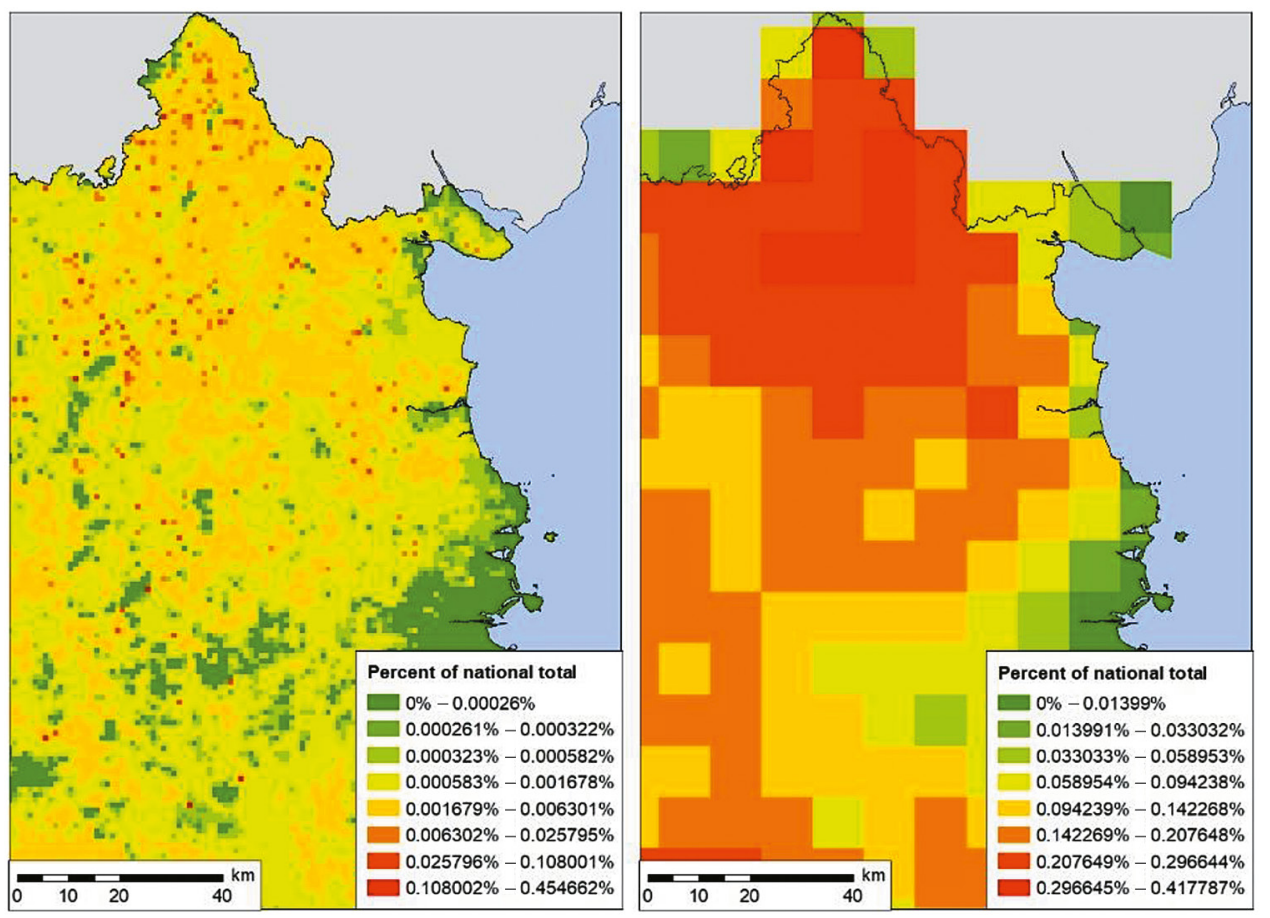

Figure 3: Share of $\mathrm{NH}_{3}$ emissions from agricultural livestock on a spatial resolution of (a) $1 \times 1 \mathrm{~km}$ and (b) $10 \times 10 \mathrm{~km}$.

Including farm-level pig and poultry data is a large improvement compared to the previous methodology. If animal numbers for other species become available on farm level as well, this can lead to further improvements in the accuracy of the spatial inventory.

Emission maps for the year 2005 for Ireland with a resolution of $50 \times 50 \mathrm{~km}$ are available on the EIONET Central Data Repository (CDR [30]). The methodologies behind the 2005 gridding are not documented, as there were no requirements to include a documentation report in the annual reporting to CLRTAP. Comparison with the 2010 and the 2015 gridded emissions is only made for national total emissions, due to large changes of the sector definitions between the reportings.

Road transport is a large source of $\mathrm{NO}_{\mathrm{x}}$ emissions. The share of national total emissions has increased from 2005 to 2015, due to decreasing emissions from combustion in industry and in public electricity and heat production. The level of details of the $50 \times 50 \mathrm{~km}$ gridding is very limited, and the most significant pattern owes to allocation of emissions from large heat and power plants. Emissions from industry are allocated according to employment statistics in the 2010 gridding, which is a weak proxy for many industries. Employment statistics does not reflect the difference between industries with a high degree of manual or automated work. An industry can have a large number of employees, but low emissions, due to the nature of the industry or the fact that production is based on, for instance, electricity from the public grid. This can lead to overestimation of emissions from industries/plants having a high degree of manual work compared to industries/plants with more automated processes. Also, the 

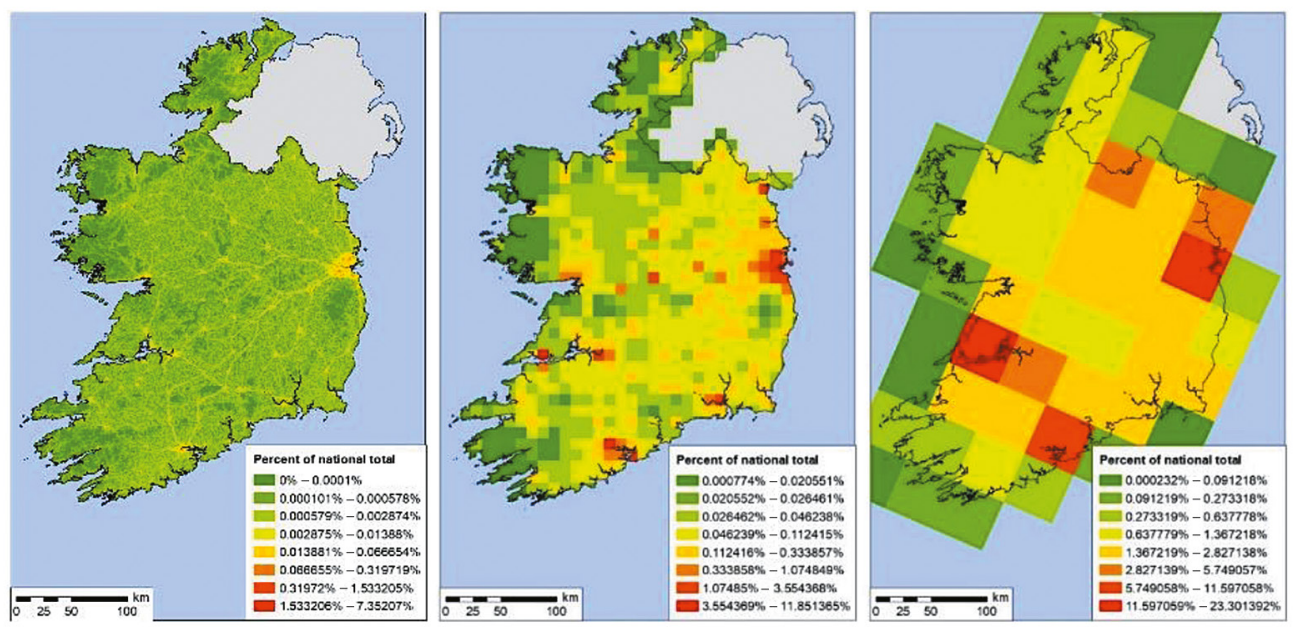

Figure 4: Share of national total $\mathrm{NO}_{\mathrm{x}}$ emissions on a spatial resolution of (a) $1 \times 1 \mathrm{~km}$; (b) $10 \times 10 \mathrm{~km}$; and (c) $50 \times 50 \mathrm{~km}$.

registered place of employment can be a main office located separately from the production facilities, where emissions would occur. Population density is included in the gridding for road transport, leading to accumulation of emissions in densely populated areas. Road transport is the largest source of $\mathrm{NO}_{\mathrm{x}}$ emissions in 2015 (35\%) followed by agricultural soils (28\%). The road network is distinct on the map with a high level of details. It is clear from the maps in Fig. 4 that the gridding has improved significantly from 2005 to 2010 and again from 2010 to 2015, regarding both the distribution methodology and the spatial resolution.

The largest sources of $\mathrm{PM}_{2.5}$ emissions are small combustion plants, road transport and industry. The methodology for industry is improved from the 2010 gridding, where it was based on employment statistics, to 2015, where the GeoKey is based on industrial heat demand by the smallest administrative unit SA. The pitfall in using employment statistics is that in many cases employees can be registered to a main office located far away from the emitting activities. Furthermore, the number of employees does not necessarily have a correlation with the emissions; e.g. some industries can produce high emissions with a low workforce and vice versa.

Residential combustion contributes $46 \%$ of the national total $\mathrm{PM}_{2.5}$ emission in 2015, and as emissions occur in low heights where people live, it is crucial to make a good distribution in order to make the spatial emissions suitable for air quality modelling and input to policymakers for development of policies and measures. As shown in Fig. 5, the 2005 map indicates that allocation to some degree is based on population or building density, as emissions are accumulated in the largest urban areas. This pattern also occurs for 2010, where the distribution is based on energy end use from Sustainable Energy Authority of Ireland [31]. A more scattered pattern occurs on the 2015 map, where the distribution is based on the number of appliances by SA from the CSO, combined with national fuel consumption in residential plants from the national energy statistics and emission factors from the national emission inventory.

Emissions from electricity and heat production, which contribute $27 \%$ of the national total $\mathrm{SO}_{2}$ emission in 2015, are allocated to the individual plants and not easy to apparent on a high 

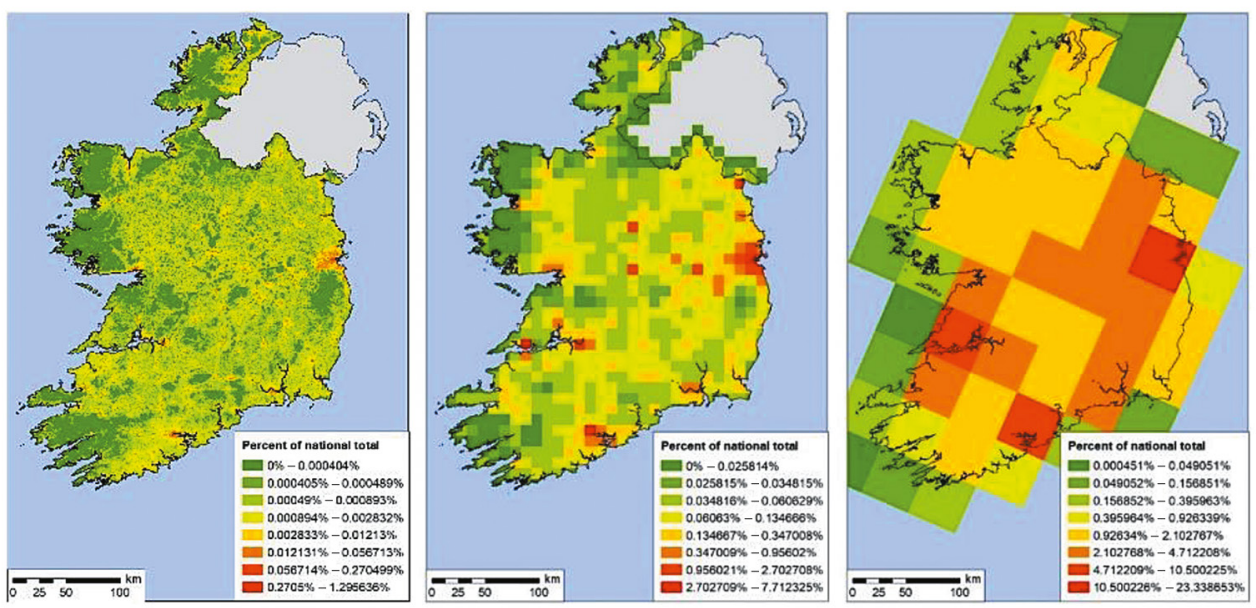

Figure 5: Share of national total $\mathrm{PM}_{2.5}$ emissions on a spatial resolution of (a) $1 \times 1 \mathrm{~km}$; (b) $10 \times 10 \mathrm{~km}$; and (c) $50 \times 50 \mathrm{~km}$.

resolution (Fig. 6). Emissions from households, which contribute 48\% in 2015, are allocated according to the distribution of appliances on SA level. Areas with high population densities are visible on the map, as emissions tend to accumulate where most people lives. The high emission levels in densely populated areas also occur on the maps with higher spatial resolution but is especially pronounced on the $50 \times 50 \mathrm{~km}$ map, which indicates that population density might have been used as proxy for the spatial distribution. A number of the large electricity and power plants are located near the densely populated areas, and using a lower spatial resolution will cause more large plants to be allocated to the same grid cell, making the large urban areas even more significant on the map.
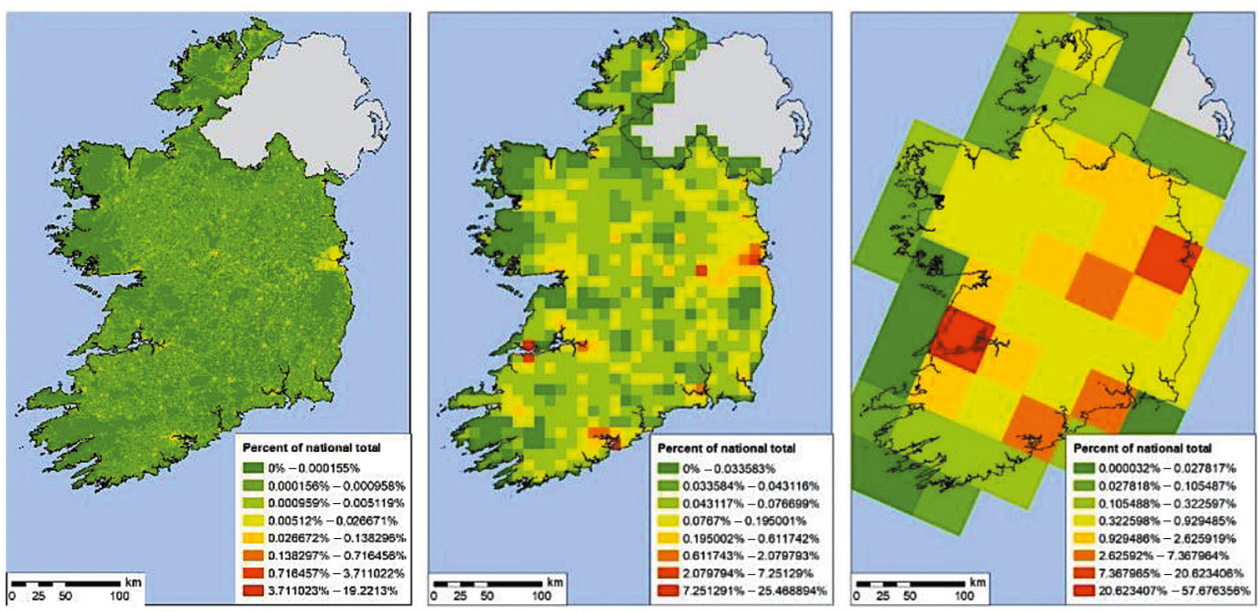

Figure 6: Share of national total $\mathrm{SO}_{2}$ emissions on a spatial resolution of (a) $1 \times 1 \mathrm{~km}$; (b) $10 \times 10 \mathrm{~km}$; and (c) $50 \times 50 \mathrm{~km}$. 

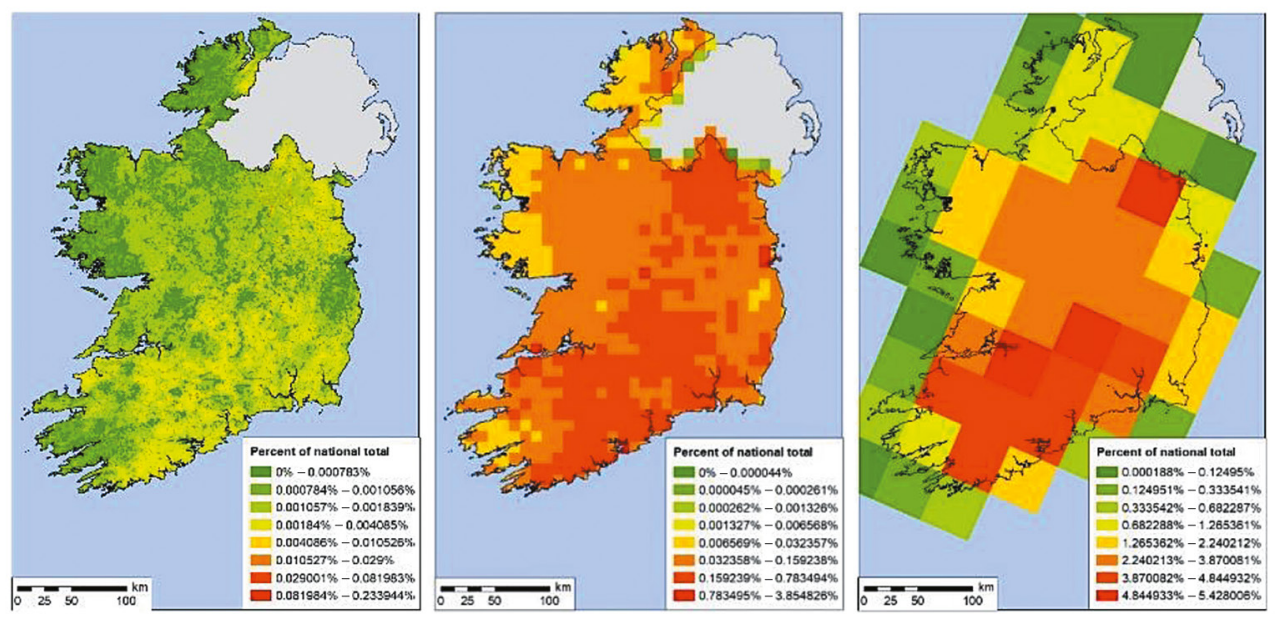

Figure 7: Share of national total $\mathrm{NH}_{3}$ emissions on a spatial resolution of (a) $1 \times 1 \mathrm{~km}$; (b) $10 \times 10 \mathrm{~km}$; and (c) $50 \times 50 \mathrm{~km}$.

Agriculture is by far the largest source of $\mathrm{NH}_{3}$ emissions. The contribution from livestock to the national total $\mathrm{NH}_{3}$ emissions has decreased as the contribution from other agricultural sources, mainly animal manure applied to soils, has increased. Emissions from agricultural soils were distributed to areas of arable land and pasture from CORINE Land Cover [32] in the 2010 gridding and to cropland and improved grassland from LPIS in the 2015 gridding. LPIS is a national dataset with a high level of detail compared to the European land cover map CORINE. In addition, the allocation of emissions from livestock to farms instead of rural areas contributes to make the spatial emissions more accurate.

As shown in Fig. 7, the general pattern is the same between the three spatial inventories. However, upon closer inspection, it becomes clear that the higher resolution and more detailed methodology allow for a much more nuanced distribution reflecting differences at the land parcel level rather than at the very aggregated level.

\section{CONCLUSIONS}

Several initiatives can be implemented to improve the accuracy of the spatial emission mapping. Disaggregation of emission sources leaves the possibility to use different GeoKeys reflecting the characteristics of the individual emission sources rather than the overall characteristics for an emission sector. This requires that the mapping is based on detailed spatial and statistical data, related to the individual emission sources and in many cases combining multiple datasets to increase the accuracy. Disaggregation only improves the spatial mapping if the underlying data are changed to higher correlated data that serve as better proxies for one or more of the emission sources included in the aggregated emission sector. Using more detailed and accurate GeoKeys enables the change to a higher spatial resolution.

All sources in the mapping should be assessed, the applicable spatial resolution should be evaluated by source and the spatial resolution of the spatial model should be chosen so that it reflects the level of detail in the resulting spatial emissions. Selecting a too low spatial resolution results in losing details, while choosing a too high spatial resolution reflects a 
level of detail that is not supported by the underlying data. Increasing the spatial resolution without using better spatial data only subdivides the grid cells without contributing further information. The optimal spatial resolution varies between the emissions sources, as some can be distributed using very detailed and accurate spatial data, e.g. point source emission, while only poor proxies can be used for other emission sources, e.g. construction and demolition, where most often neither location nor activity data are available. In the spatial mapping model, emissions from construction and demolition are distributed evenly to all buildings.

As shown for selected examples above, using data at a more disaggregated level and a higher spatial resolution results in a more detailed spatial emission mapping with higher accuracy, when based on appropriate background data. The improvements from the coarse $50 \times 50 \mathrm{~km}$ resolution spatial inventory to both the $10 \times 10 \mathrm{~km}$ and the $1 \times 1 \mathrm{~km}$ spatial inventories are significant, especially for $\mathrm{NO}_{\mathrm{x}}, \mathrm{SO}_{2}$ and $\mathrm{PM}_{2.5}$. For $\mathrm{NH}_{3}$, the improvement can seem less pronounced when observing the maps (Fig. 7), but at the local level, the changes are still pronounced between the coarse and finer-resolution spatial inventories. This is illustrated in the mapping of $\mathrm{NH}_{3}$ emissions from livestock (Fig. 3), where the difference of allocating the emissions from livestock to the entire land area versus allocating emissions from animal housing to the actual location becomes very clear. For local scale modelling, the difference in these approaches would lead to very different results.

The results obtained using the MapEIre model will provide improved input data to air quality modelling, contributing to more accurate model results, and will allow for more targeted development of policies and measures.

In future work, the emphasis should be on refining methodologies as a further increase in the resolution is unlikely to improve the accuracy of the spatial inventory, as very few datasets are available to support a resolution of e.g. $100 \times 100 \mathrm{~m}$.

\section{ACKNOWLEDGEMENTS}

This work has been funded by Ireland's Environmental Protection Agency Research Call 2015 (Ref: 2015-CCRP-MS.26).

The authors would like to thank Paul Duffy, Bernard Hyde and Ann Marie Ryan from the emission inventory team at Ireland's Environmental Protection Agency (EPA) for the access to detailed data from the emission inventory as well as valuable discussions on data and national circumstances. Also, the authors would like to thank David Kelleghan for providing highly detailed data on pigs and poultry houses.

The authors would like to acknowledge the advice and help provided by members of the Steering Committee of the project.

\section{REFERENCES}

[1] World Health Organization, 9 Out of 10 People Worldwide Breathe Polluted Air, but More Countries Are Taking Action, 2018, available at http://www.who.int/news-room/ detail/02-05-2018-9-out-of-10-people-worldwide-breathe-polluted-air-but-more-countries-are-taking-action (accessed 6 December 2018).

[2] Brandt, J., Silver, J.D., Christensen, J.H., Andersen, M.S., Bønløkke, J., Sigsgaard, T., Geels, C., Gross, A., Hansen, A.B., Hansen, K.M., Hedegaard, G.B., Kaas, E. \& Frohn, L.M., Contribution from the ten major emission sectors in Europe and Denmark to the health-cost externalities of air pollution using the EVA model system - an integrated modelling approach. Atmospheric Chemistry and Physics, 13(15), pp. 7725-7746, 2013. https://doi.org/10.5194/acp-13-7725-2013. 
[3] European Environment Agency (EEA), European Union Emission Inventory Report 1990-2015 under the UNECE Convention on Long-range Transboundary Air Pollution (LRTAP). EEA Report No 9/2017, European Environment Agency: Kongens Nytorv 6, 1050 Copenhagen K, Denmark, 2017.

[4] EDGAR - Emissions Database for Global Atmospheric Research. European Commission, 2017, available at http://edgar.jrc.ec.europa.eu/index.php (accessed 14 February 2018).

[5] Umweltbundesamt, A High Resolution European Emission Data Base for the Year 2005, Federal Environment Agency (Umweltbundesamt): Wörlitzer Platz 1, 06844 Dessau-Roßlau, Germany, 2013.

[6] UNECE, Guidelines for Reporting Emissions and Projections Data under the Convention on Long-range Transboundary Air Pollution, ECE/EB.AIR/125, UNITED NATIONS PUBLICATION Copyright ${ }^{\circledR}$ : United Nations, 2015.

[7] Bo, Y., Cai, H. \& Xie, S.D., Spatial and temporal variation of historical anthropogenic NMVOCs emission inventories in China. Atmospheric Chemistry and Physics, $\mathbf{8}$, pp. 7297-7316, 2008. https://doi.org/10.5194/acp-8-7297-2008.

[8] Sahu, S.K., Beig, G. \& Parkhi, N.S., Emissions inventory of anthropogenic $\mathrm{PM}_{2.5}$ and $\mathrm{PM}_{10}$ in Delhi during Commonwealth Games 2010. Atmospheric Environment, 45, pp. 6180-6190, 2011. https://doi.org/10.1016/j.atmosenv.2011.08.014.

[9] Dalvi, M., Beig, G., Patil, U., Kaginalkar, A., Sharma, C. \& Mitra, A.P., A GIS based methodology for gridding of large-scale emission inventories: application to carbonmonoxide emissions over Indian region. Atmospheric Environment, 40, pp. 2995-3007, 2006. https://doi.org/10.1016/j.atmosenv.2006.01.013.

[10] Wu, S.-P., Zhang, Y.-J., Schwab, J.J., Li, Y.-F., Liu, Y.-L. \& Yuan, C.-S., High-resolution ammonia emissions inventories in Fujian, China, 2009-2015. Atmospheric Environment, 162, pp. 100-114, 2017. https://doi.org/10.1016/j.atmosenv.2017.04.027.

[11] Skjøth, C.A., Geels, C., Berge, H., Gyldenkærne, S., Fagerli, H., Ellermann, T., Frohn, L.M., Christensen, J., Hansen, K.M., Hansen, K. \& Hertel, O., Spatial and temporal variations in ammonia emissions - a freely accessible model code for Europe. Atmospheric Chemistry and Physics, 11, pp. 5221-5236, 2011. https://doi.org/10.5194/acp11-5221-2011.

[12] Hellsten, S., Dragosits, U., Place, C.J., Vieno, M., Dore, A.J., Misselbrook, T.H., Tang, Y.S. \& Sutton, M.A., Modelling the spatial distribution of ammonia emissions in the UK. Environmental Pollution, 154, pp. 370-379, 2008. https://doi.org/10.1016/j.envpol.2008.02.017.

[13] Puliafito, S.E., Allende, D., Pinto, S. \& Castesana, P., High resolution inventory of GHG emissions of the road transport sector in Argentina. Atmospheric Environment, 101, pp. 303-311, 2015. https://doi.org/10.1016/j.atmosenv.2014.11.040.

[14] Plejdrup, M.S., Nielsen, O.-K. \& Brandt, J., Spatial emission modelling for residential wood combustion in Denmark. Atmospheric Environment, 144, pp. 389-396, 2016. https://doi.org/10.1016/j.atmosenv.2016.09.013.

[15] Johansson, L., Jalkanen, J.-P. \& Kukkonen, J., Global assessment of shipping emissions in 2015 on a high spatial and temporal resolution. Atmospheric Environment, 167, pp. 403-415, 2017. https://doi.org/10.1016/j.atmosenv.2017.08.042.

[16] Castesana, P., Dawidowski, L., Finster, L., Gomez, D. \& Taboada, M., Ammonia emissions from the agriculture sector in Argentina; 2000-2012. Atmospheric Environment, 178, pp. 293-304, 2018. https://doi.org/10.1016/j.atmosenv.2018.02.003. 
[17] Guttikunda, S.K. \& Calori, G., A GIS based emissions inventory at $1 \mathrm{~km} \mathrm{x} 1 \mathrm{~km}$ spatial resolution for air pollution analysis in Delhi, India. Atmospheric Environment, 67, pp. 101-111, 2013. https://doi.org/10.1016/j.atmosenv.2012.10.040.

[18] Tian, Y.Q., Radke, J.D., Gong, P. \& Yu, Q., Model development for spatial variation of $\mathrm{PM}_{2.5}$ emissions from residential wood burning. Atmospheric Environment, 38, pp. 833-843, 2004. https://doi.org/10.1016/j.atmosenv.2003.10.040.

[19] Qi, J., Zheng, B., Li, M., Yu, F., Chen, C., Liu, F., Zhou, X., Yuan, J., Zhang, Q. \& He, K., A high-resolution air pollutants emission inventory in 2013 for the Beijing-TianjinHebei region, China. Atmospheric Environment, 170, pp. 156-168, 2017. https://doi. org/10.1016/j.atmosenv.2017.09.039.

[20] Kannari, A., Tonooka, Y., Baba, T. \& Murano, K., Development of multiple-species $1 \mathrm{~km} \times 1 \mathrm{~km}$ resolution hourly basis emissions inventory for Japan. Atmospheric Environment, 41, pp. 3428-3439, 2007. https://doi.org/10.1016/j.atmosenv.2006.12.015.

[21] Tsilingiridis, G., Sidiropoulos, C., Pentaliotis, A., Evripidou, C., Papastavros, C., Mesimeris, T. \& Papastavrou, M., A spatially allocated emissions inventory for Cyprus. Global NEST Journal, 12(434), pp. 99-107, 2010. https://doi.org/10.30955/gnj.000682.

[22] Plejdrup, M.S. \& Gyldenkærne, S., Spatial distribution of emissions to air - the SPREAD model. National Environmental Research Institute, Aarhus University, Denmark, NERI Technical Report no. 823, 72 pp., 2011.

[23] Nyíri, A., Emissions for CLRTAP modelling - experience and feedback. Presented on 25 April 2018 Workshop on Verification of Emission Estimates, Sofia, 2018.

[24] FAIRMODE, available at http://fairmode.jrc.ec.europa.eu/.

[25] de Kluizenaar, Y., Aherne, J. \& Farrell, E.P., Modelling the spatial distribution of $\mathrm{SO}_{2}$ and $\mathrm{NO}_{\mathrm{x}}$ emissions in Ireland. Environmental Pollution, 112, pp. 171-182, 2001. https:// doi.org/10.1016/S0269-7491(00)00120-2.

[26] AEA, Mapping Methods for Gridded Data, 2012. Unpublished.

[27] Plejdrup, M.S., Nielsen, O.-K. \& Bruun, H.G., Spatial high-resolution mapping of national emissions. WIT Transactions on Ecology and the Environment, Vol. 230, WIT Press: Ashurst Lodge, Ashurst Southampton SO40 7AA, UK, 2018, ISBN 978-1-78466-269-1.

[28] The AmmoniaN2K Project, available at https://www.ucd.ie/ammonian2k/ (accessed 6 December 2018).

[29] European Union, 2010, Directive 2010/75/EU of the European Parliament and of the Council of 24 November 2010 on industrial emissions (integrated pollution prevention and control).

[30] CDR, available at https://cdr.eionet.europa.eu/.

[31] Duffy, P., Hyde, B., Hanley, E. \& Barry, S., Irelands Informative Inventory Report 2012, Irish Environmental Protection Agency: An Ghníomhaireacht um Chaomhnú Comhshaoil, PO Box 3000, Johnstown Castle, Co. Wexford. Ireland, 2012.

[32] Copernicus Land Portal, CORINE Land Cover, available at https://land.copernicus.eu/ pan-european/corine-land-cover. 